\title{
PROGRAMA MAIS EDUCAÇÃO E PROGRAMA NOVO MAIS EDUCAÇÃO: PONTOS E CONTRAPONTOS
}

\author{
Samanta Antunes Kasper , Alana Paula de Oliveira, Renata Portela Rinaldi \\ Universidade Estadual Paulista - UNESP, Programa de Pós Graduação em Educação, Presidente Prudente, SP. E-mail: \\ samantakasper@hotmail.com.
}

\section{RESUMO}

O presente estudo, de caráter documental, visa caracterizar o Programa Mais Educação e o Programa Novo Mais Educação, bem como discutir suas semelhanças e diferenças em termos de objetivos e proposta de ampliação da jornada escolar. Para tal, nos valemos de documentos legais e normativos que instituíram e orientaram a implementação de tais programas. Na última década, programas de níveis federais foram criados para ampliar a jornada escolar, mas com intenções distintas. O Programa Mais Educação - descontinuado no ano de 2016 - propunha, de certa forma, contemplar a formação integral dos estudantes, enquanto que o objetivo central do Programa Novo Mais Educação volta-se a complementar estudos referentes à Língua Portuguesa e Matemática para melhorar o desempenho escolar dos estudantes em avaliações externas e em larga escala. Concluímos que estamos diante de um retrocesso no campo da política educacional, reducionismo, descaracterização e descontinuidade de propostas alicerçadas em contextos políticos.

Palavras-chave: Educação Integral. Programa Mais Educação. Programa Novo Mais Educação. Ampliação da jornada escolar.

\section{MORE EDUCATION PROGRAM AND NEW MORE EDUCATION PROGRAM: POINTS AND COUNTERPOINTS}

\begin{abstract}
This documental study aims to characterize the "More Education Program" and the "New More Education Program", as well as to discuss its similarities and differences considering its objectives and proposal to extend the school day. To do so, we rely on legal and normative documents that instituted and guided the implementation of such programs. In the last decade, programs at federal levels have been created to extend the school day, but with different intentions. The "More Education Program" - discontinued in 2016 - proposed, somehow, to contemplate the integral formation of students, while the main objective of the "New More Education Program" is to complement studies related to the Portuguese Language and Mathematics aiming to improve students' performance in external and large-scale assessments. We concluded that we are facing a regression in the field of educational policy, reductionism, decharacterization and discontinuity of proposals based on political contexts.

Keywords: Integral Education. More Education Program. New More Education Program. Extension of the school day.
\end{abstract}




\section{INTRODUÇÃO}

Sabemos que a temática da educação integral perpassou, ao longo do século $\mathrm{XX}$, a agenda político-educacional dos diferentes entes federativos do Brasil por diversas vezes e está, atualmente, presente nas agendas dos diferentes tipos de governo, no âmbito nacional e local (PARENTE, 2017).

Compreendermos por educação integral uma formação completa que englobe todos os aspectos do desenvolvimento (cognitivo, afetivo, físico, linguístico, político, cultural, moral, ético e estético). Uma formação emancipadora que se propõe a educar integralmente as crianças, os adolescentes e os jovens, sem distinção ou privilégios de qualquer natureza. Uma educação integral em que a formação completa seja integrada e não dissociada do currículo escolar, uma vez que todos os componentes curriculares são inerentes a essa formação (CAVALIERE, 2002; COELHO, 2009).

Acreditamos que o espaço escolar é adequado para se propor uma educação integral e pode se fortalecer com o tempo integral a partir da perspectiva de educação democrática que vislumbra mais qualidade de vivências e não apenas mais tempo de permanência da criança na escola. A educação em tempo integral não se limita à ampliação da jornada escolar, mas nas possibilidades de se ter mais tempo para realizar atividades que promovam o desenvolvimento integral dos estudantes.

De acordo com Cavaliere (2010), quando a educação era destinada à parcela privilegiada da sociedade, a mesma se dava em tempo integral; porém, para dar acesso a mais alunos, a jornada diária foi sendo reduzida.

Em meio à expansão industrial, fenômeno mundial que também atingiu o contexto brasileiro, nos anos de 1920, surgiu a necessidade de preparar profissionais para o mercado de trabalho. Diferentes correntes políticas e ideológicas delinearam propostas de educação integral, como as correntes elitistas e autoritárias que prezavam pelo controle social e pela distribuição dos indivíduos em segmentos distintos e hierarquizados; a proposta da Ação Integralista Brasileira (AIB) que pretendia elevar o nível cultural da população, por meio de uma educação moralizadora e doutrinária que envolvia o Estado, a família e a religião; e a proposta dos liberais que viam a democracia, pautada na cooperação e na participação, como princípio da educação integral para se reconstruir as bases sociais e renovar o papel da escola (CAVALIERE, 2010).

A ideia de renovação da escola no Brasil teve seu ápice no ano de 1932, com o Manifesto da Escola Nova, que defendia a universalização da escola pública, laica e gratuita. A corrente pedagógica escolanovista, do início do século $X X$, refletia a necessidade de se reformular a vocação da escola, ampliando e fortalecendo as suas funções. No Manifesto são mencionados três vezes o termo "educação integral", relacionado à ideia de uma formação que favoreça as diversas dimensões do indivíduo (CAVALIERE, 2002; GONÇALVES, 2006).

Anísio Teixeira era integrante dessa corrente e acreditava que a escola pública de tempo integral era uma possibilidade de expansão qualitativa da educação, principalmente aos socialmente marginalizados. Ao final da década de 1940, na posição de Secretário de Educação e Saúde da Bahia, Anísio Teixeira construiu um projeto para suprir a demanda por vagas nas escolas públicas. Na oportunidade, pôde se concretizar a ideia de formação de hábitos de pensar, fazer, conviver e participar democraticamente em sociedade. Implantou-se, então, no Estado da Bahia, a primeira experiência brasileira de escolas públicas de tempo integral - o Centro Educacional Carneiro Ribeiro - as quais ofereciam atividades em dois períodos, um para o cumprimento dos componentes curriculares e o outro para a realização de atividades sociais, físicas e artísticas (COELHO, 2009).

O projeto reformista de Anísio Teixeira perdeu suas forças com o novo período de autoritarismo instalado no Brasil. A sua proposta não teve continuidade com o golpe militar de 1964 e com o seu afastamento da vida política. Após essa experiência do Centro Educacional 
Carneiro Ribeiro, na Bahia, surgiram outras tentativas de expansão da jornada escolar: os Ginásios Vocacionais no Estado de São Paulo, proposto pelo Secretário de Educação Luciano Vasconcellos de Carvalho, na década de 1960, com seis unidades que duraram oito anos; o Programa de Formação Integral da Criança no Estado de São Paulo, entre os anos de 1986 e 1993, que atendeu cerca de $10 \%$ dos alunos matriculados no ensino fundamental; os Centros de Atenção Integral à Criança e ao Adolescente (CAICs), implantados em 444 escolas em vários estados brasileiros a partir de 1991 pelo presidente Fernando Collor de Mello (CELLA, 2010).

Com proposta próxima à de Anísio Teixeira, a experiência mais duradoura e que teve mais repercussão no Brasil foi a dos Centros Integrados de Educação Pública (CIEPs), implantada na rede pública estadual pelo professor Darcy Ribeiro no Estado do Rio de Janeiro, durante as duas gestões do governador Leonel Brizola (1983-1994). Tais experiências, alicerçadas em partidos ou gestores políticos, não resistiram às trocas de governo tal como foram planejadas, principalmente devido ao paradigma de racionalização de gastos com a educação e à cultura de turnos únicos (ESQUINSANI, 2008).

Como vimos, tem se tentado ampliar a jornada escolar antes mesmo da promulgação da Constituição Federal de 1988. Contudo, é a partir desse marco democrático que se regulamenta o direito de todos à educação de qualidade, pública e gratuita, sendo o principal respaldo nacional, tanto para as produções científicas como para as políticas públicas educacionais instituídas posteriormente. De acordo com a Constituição Federal (BRASIL, 1988), "a educação visa ao pleno desenvolvimento da pessoa, ao seu preparo para o exercício da cidadania e a sua qualificação para o trabalho". Dessa forma, interpretamos que a compreensão de educação expressa na CF88 já prevê o desenvolvimento de uma educação integral pelas instituições educativas, principalmente a escola, que devem garantir uma educação que ultrapasse a formação cognitiva e o cumprimento de conteúdos curriculares.

Dessa forma, é possível notar que é um desafio, desde longa data, garantir às crianças e adolescentes uma formação escolar que seja produtora de cidadania. A proposta de educação de tempo integral apresenta-se como uma possibilidade para que esse e outros objetivos sejam alcançados.

Recentemente, dois programas distintos de nível federal foram implementados em escolas públicas de educação básica: o Programa Mais Educação (2007-2016) e o Programa Novo Mais Educação (2016-atual). Nesse sentido, no presente trabalho, temos o intuito de caracterizar cada programa, bem como discutir suas semelhanças e diferenças em termos de objetivos e proposta de ampliação da jornada escolar.

\section{METODOLOGIA}

Este trabalho é decorrente de pesquisas documentais realizadas no âmbito de investigações sobre educação integral ${ }^{1}$. A pesquisa documental "[...] propõe-se a produzir novos conhecimentos, crias novas formas de compreender os fenômenos e dar a conhecer a forma como estes têm sido desenvolvidos." (SÁ-SILVA; ALMEIDA; GUINDANI, 2009, p. 14).

Flick (2009) salienta que em um estudo documental os documentos devem ser entendidos como "meios de comunicação", pois foram elaborados com algum propósito e para alguma finalidade, sendo destinado para que alguém tivesse acesso à eles. Desse modo, ressalta a importância de compreender quem o produziu, sua finalidade, para quem foi elaborado, a sua intencionalidade e que não devem ser utilizados como "contêineres de informações". Devem ser entendidos como uma forma de contextualização da informação e analisados como "dispositivos

\footnotetext{
${ }^{1}$ Pesquisa de Doutorado em Educação: “Educação Integral X Escola de Tempo Integral: explorando os espaços para a educação em valores”. E pesquisa de Mestrado em Educação: "Mal-estar no trabalho docente na escola pública de tempo integral" (FAPESP). Ambas as pesquisas estão vinculadas à uma pesquisa maior desenvolvida na FCT/UNESP e intitulada "Rede de pesquisa e formação sobre educação integral: experiências, movimentos, inovação e desafios contemporâneos".
} 
comunicativos metodologicamente desenvolvidos na produção de versões sobre eventos" (FLICK, 2009, p. 234).

Para atender ao objetivo deste estudo, nos apoiamos em documentos legais e normativos referentes aos programas Mais Educação (PME) e Novo Mais Educação (PNME). No que tange ao PME, temos como base os seguintes documentos: Portaria Interministerial no 17, Decreto no 7.083, Cadernos da Série Mais Educação. E no que se refere ao PNME, consideramos a Portaria MEC no 1.144, o Caderno Orientador e o Caderno de orientações pedagógicas.

\section{RESULTADOS}

Visando uma análise comparativa entre os programas, faz-se necessário a contextualização de ambas as propostas.

O Programa Mais Educação (PME) criado pelo Ministério da Educação foi instituído pela Portaria Interministerial no 17/2007 e regulamentado pelo Decreto 7.083/10. O mesmo é considerado uma política educacional de indução de uma educação integral nas escolas brasileiras. Mais especificamente, a proposta tinha como objetivo:

[...] contribuir para a formação integral de crianças, adolescentes e jovens, por meio da articulação de ações, de projetos e de programas do governo federal e suas contribuições às propostas, visões e práticas curriculares das redes públicas de ensino e das escolas, alterando o ambiente escolar e ampliando a oferta de saberes, métodos, processos e conteúdos educativos (BRASIL, 2007, p. 2).

O PME congregava ações conjuntas com outros Ministérios, a saber: Ministério da Educação, o Ministério do Desenvolvimento Social e Combate à Fome, o Ministério da Ciência e Tecnologia, o Ministério do Esporte, o Ministério do Meio Ambiente, o Ministério da Cultura, o Ministério da Defesa e a Controladoria Geral da União. A proposta trata-se do esforço para construção de uma ação intersetorial entre as políticas públicas educacionais e sociais, contribuindo para a diminuição das desigualdades educacionais e para a valorização da diversidade cultural brasileira.

A estratégia proporcionava a ampliação de tempo, espaços e oportunidades educacionais baseando-se no pressuposto da formação integral, sendo a mesma expressa pela conexão das aprendizagens da sala de aula, as vivências em oficinas de diversas áreas, os saberes comunitários que adentram a escola por meio de diferentes parcerias, entre outros fatores (VALENTINI; ZUCCHETTI, 2017).

No ano de 2016, o Brasil teve uma grande crise política que gerou um golpe de estado e culminou com o impeachment da presidenta eleita, Dilma Rousseff, aprovado pelo senado federal no dia 31 de agosto daquele ano. O executivo nacional foi assumido interinamente pelo então vice-presidente, período no qual aprofundou a desestabilização e a incerteza da continuidade das políticas públicas e programas. Desse modo, o Programa Mais Educação foi substituído pelo Programa Novo Mais Educação (PNME), o qual apresenta outros fundamentos, objetivos e procedimentos de implementação nas escolas.

Instituído pela Portaria n. 1.144 de 2016, o referido programa pertence à Secretaria de Educação Básica (SEB) e objetiva “[...] melhorar a aprendizagem em língua portuguesa e matemática no ensino fundamental, por meio da ampliação da jornada escolar de crianças e adolescentes (...)" (BRASIL, 2016). A execução desse programa se dá por meio de articulação institucional e cooperação com as secretarias estaduais, distrital e municipais de educação, através do apoio técnico e financeiro do Ministério da Educação (MEC).

Nesse sentido, o acréscimo de tempo na escola se restringe à complementação de estudos, principalmente em Língua Portuguesa e Matemática. Nesse formato, não há uma proposta de educação integral ou de educação em tempo integral. 


\section{DISCUSSÕES}

Diferente do Programa Mais Educação, vigente até 2016, que também tinha o intuito de melhorar a aprendizagem, mas incluía uma proposta de educar integralmente as crianças, adolescente e jovens com atividades que envolviam aspectos culturais, éticos e diversas linguagens como a música, dança e a Arte, o PNME aborda, de maneira explícita, a ideia de uma escola de tempo integral na tentativa de melhorar a aprendizagem e o rendimento dos alunos para superar o fracasso escolar e alcançar resultados quantitativos em avaliações externas e em larga escala de Língua Portuguesa e de Matemática.

Embora PME e PNME apresentem a ampliação da jornada escolar, a concepção de educação que trazem é divergente. O PNME volta-se para uma direção contrária do que era proposto pelo PME:

[...] é importante ressaltar que o aumento do tempo escolar necessário à Educação Integral que propomos não objetiva dar conta apenas dos problemas que os alunos enfrentam devido ao baixo desempenho nos diversos sistemas de avaliação, pois o que se pode constatar, em alguns casos, é que o aumento da jornada de trabalho escolar dos alunos em disciplinas específicas, como Matemática ou Língua Portuguesa, tem gerado processos de hiperescolarização, que não apresentam os resultados desejados (BRASIL, 2009, p. 36).

O foco em apenas algumas disciplinas resulta na hiperescolarização. Os componentes curriculares de Matemática e Língua Portuguesa são colocados em posição hierarquicamente superior às outras aprendizagens que constituem a integralidade dos sujeitos. Tal fator nos leva a perceber grande retrocesso na atual proposta e que os reais aspectos e ideais formativos da educação integral não são considerados.

Cavalieri (2007, p.1022) aponta que "[...] uma concepção de educação integral, que envolva múltiplas dimensões da vida das crianças e adolescentes, precisa de um tipo de escola onde ocorram vivências reflexivas".

\section{CONCLUSÃO}

É possível perceber que há demanda e necessidade de Educação Integral e(m) Tempo Integral no campo educacional e que há um caminhar no decorrer dos anos para a ampliação do tempo escolar.

Um marco no que se refere à política de indução da educação integral nas escolas públicas brasileiras foi o Programa Mais Educação. Este foi substituído pelo Programa Novo Mais Educação que dá ênfase à leitura, escrita e cálculo, e desvaloriza as outras áreas do conhecimento.

O atual Programa reforça a perspectiva de valorização das políticas de avaliação de sistemas públicos de educação, conferindo importância e relevância aos exames de proficiência. Dessa forma, o Programa Novo Mais Educação arrebata dos alunos das escolas públicas o direito à educação integral, criando uma perspectiva de ampliação da jornada escolar para complementar os estudos de componentes curriculares do ensino regular, ou seja, sem a preocupação com o desenvolvimento global do estudante.

Devido às diversas alterações que a proposta inicial sofreu, podemos afirmar que estamos diante de um retrocesso nas políticas educacionais, reducionismo e descaracterização de um Programa que sequer alcançou o ápice do que fora inicialmente proposto. Portanto, novamente, estamos diante de propostas que se limitam a contextos históricos e políticos do país, o que nos conduz ao seguinte questionamento: o que há de novo no Novo Mais Educação?

De antemão, acreditamos que as crianças, os adolescentes e os jovens apenas estão mais tempo na escola realizando as mesmas atividades, pois não nos resta dúvidas de que é ofertado mais do mesmo. 


\section{REFERÊNCIAS}

BRASIL. Constituição (1988). Constituição da República Federativa do Brasil: promulgada em 5 de outubro de 1988. Organização do texto por Juarez de Oliveira. 4. ed. São Paulo: Saraiva, 1990. 168 p. (Série Legislação Brasileira)

. Ministério da Educação. Secretaria de Educação Continuada, Alfabetização e Diversidade (Secad). Educação Integral: texto referência para o debate nacional. Brasília, 2009. Acesso em: 19 mar. 2018.

. Portaria Normativa Interministerial $n^{\circ} 17$, de 24 de abril de 2007. Institui o Programa Mais Educação que visa fomentar a educação integral de crianças, adolescentes e jovens, por meio do apoio a atividades socioeducativas no contraturno escolar. Brasília: Diário Oficial da União.

. Portaria n. 1.144, de 11 de outubro de 2016. Institui o Programa Novo Mais

Educação que visa melhorar a aprendizagem em língua portuguesa e matemática no ensino fundamental. Diário Oficial da União, Brasília, 2016.

. Educação Integral: uma nova identidade para a realidade brasileira? Educ. Soc., Campinas, v. 23, n. 81, 2002, p. 247-270. Disponível em: < http://www.scielo.br/pdf/es/v23n81/13940.pdf>. Acesso em: 18 jul. 2018.

. Tempo de escola e qualidade na educação pública. Educação e Sociedade. Campinas, v.

28, n.100, p. 1015-1035, out. 2007. Disponível em: <http://www.scielo.br/scielo.php?pid=S010173302007000300018\&script=sci_abstract\&tlng=pt>. Acesso em: 19 mar. 2018.

CAVAliere, A. M. Anísio Teixeira e a Educação Integral. Paidéia, maio-ago. 2010, v. 20, n. 46, p. 249-259.

CELLA, R. Educação de tempo integral no Brasil: história, desafios e perspectivas. Dissertação (Mestrado). Faculdade de Educação. Universidade de Passo Fundo. Passo Fundo, 2010.

COELHO, L. M. C. História(s) da Educação Integral. In: MAURíCIO, L. V. (Org.). Em Aberto: educação integral e tempo integral, Brasília, v. 22, n. 80, p. 83-96, abr. 2009..

ESQUINSANI, R. S. S. A trajetória da escola em tempo integral no Brasil: revisão histórica. In: Congresso Brasileiro De História Da Educação, 5. Aracaju. Anais... 2008. Aracaju, 2008.

FLICK, U. Introdução à pesquisa qualitativa. COSTA, J. E. (Trad.). 3 ed. Porto Alegre: Artmed, 2009.

GONÇALVES, A. S. Reflexões sobre a educação integral e a escola de tempo integral. Cadernos Cenpec, n. 2 - Educação Integral, 2o semestre, 2006.

PARENTE, C. M. D. Políticas de Educação Integral em Tempo Integral à Luz da Análise do Ciclo da Política Pública. Educação \& Realidade, Porto Alegre, 2017.

SÁ-SILVA, J. R.; ALMEIDA, C. D., GUINDANI, J. F. Pesquisa documental: pistas teóricas e metodológicas. Rev. Bras. de História \& Ciências Sociais. n. I, p. 1-15, jul., 2009. 
VALENTINI, C. A; ZUCCHETTI, D. T. A educação integral no Brasil: das experiências históricas ao programa mais educação. Comunicações, Piracicaba v. 24 n. 2 p. 199-214 maio-agosto 2017. Disponível em: <https://www.metodista.br/revistas/revistasunimep/index.php/comunicacoes/article/view/2825> Acesso em: 05 jul. 2018. 